\title{
Repercussions of the COVID-19 Response in Pregnant Women in Western Uganda: Knowledge, Behavior, and Emotional State after the First Lockdown in 2020
}

\author{
Stefanie Theuring ${ }^{1, *}$, Agnes Kengonzi ${ }^{2}$ (D) Lorena Hafermann $^{3}$, Carolin Herrmann ${ }^{3}(\mathbb{D}$, \\ Steven Ndugwa Kabwama ${ }^{4}$ id and John Rubaihayo ${ }^{2}$
}

check for updates

Citation: Theuring, S.; Kengonzi, A.; Hafermann, L.; Herrmann, C.; Kabwama, S.N.; Rubaihayo, J. Repercussions of the COVID-19 Response in Pregnant Women in Western Uganda: Knowledge, Behavior, and Emotional State after the First Lockdown in 2020. Int. J. Environ. Res. Public Health 2021, 18, 7817. https://doi.org/10.3390/ ijerph18157817

\section{Academic Editors:}

Robert Colebunders and Jacob Souopgui

Received: 24 June 2021

Accepted: 18 July 2021

Published: 23 July 2021

Publisher's Note: MDPI stays neutral with regard to jurisdictional claims in published maps and institutional affiliations.

Copyright: (c) 2021 by the authors. Licensee MDPI, Basel, Switzerland. This article is an open access article distributed under the terms and conditions of the Creative Commons Attribution (CC BY) license (https:// creativecommons.org/licenses/by/ $4.0 /$ )
1 Institute of Tropical Medicine and International Health, Charité-Universitätsmedizin, Corporate Member of Freie Universität Berlin, Humboldt-Universität zu Berlin, and Berlin Institute of Health 13353 Berlin, Germany

2 School of Health Sciences, Mountains of the Moon University, Fort Portal P.O. Box 837, Uganda; kenaggie24@gmail.com (A.K.); rubaihayoj@yahoo.co.uk (J.R.)

3 Institute of Biometry and Clinical Epidemiology, Charité-Universitätsmedizin, Corporate Member of Freie Universität Berlin, Humboldt-Universität zu Berlin, and Berlin Institute of Health, 10117 Berlin, Germany; lorena.hafermann@charite.de (L.H.); carolin.herrmann@charite.de (C.H.)

4 School of Public Health, Makerere University, Kampala 7062, Uganda; skabwama@musph.ac.ug

* Correspondence: Stefanie.theuring@charite.de; Tel.: +49-30-450565767

\begin{abstract}
Limited research exists on pregnant women's knowledge, attitudes, and behavior concerning COVID-19 in sub-Saharan Africa. We performed a cross-sectional study among 648 pregnant women in Fort Portal, Uganda, after the first lockdown starting in June 2020. Structured interviews were conducted at three different facilities during routine antenatal care, assessing sociodemographic background, knowledge of COVID-19, prevention behavior adherence, and psycho-emotional stress levels. We performed descriptive analyses and examined associated factors using multivariable logistic regression. In Fort Portal Region, 32.8\% of pregnant women had a higher knowledge regarding the COVID-19 pandemic, while all women at least heard of COVID-19. 88.6\% of the women showed low self-reported prevention behavior adherence. More than one third of the pregnant women experienced high psycho-emotional stress related to the pandemic (39.8\%). The odds for psycho-emotional stress were increased among the age group 21-30 years (AOR 1.97; 95\% CI 1.183.35 ) compared to women under the age of 21 , and decreased in single or divorced women compared to women in partnerships (AOR 0.42; 0.22-0.77) and in women having less COVID-19-related knowledge (AOR 0.40; 0.27-0.58). In conclusion, prevention behavior adherence seemed challenging, and psycho-emotional stress was ubiquitous among our cohort. To avoid adverse consequences in maternal and neonatal health, campaigns for hygiene but also women's emotional state should be a major focus of community healthcare in exceptional times such as the SARS-CoV-2 pandemic.
\end{abstract}

Keywords: Uganda; COVID-19; KAP study; knowledge; prevention behavior; emotional stress; pregnant women

\section{Introduction}

In early 2020, when the World Health Organization (WHO) declared the emerging respiratory infection Coronavirus disease 2019 (COVID-19) to be a public health emergency of international concern [1], one of the greatest fears of the international health community was the spread of the virus to low- and middle- income countries with inadequate and often non-functional health systems [2]. Despite the fact that compared to other regions of the world, most African countries were initially spared the main burden of the pandemic [3], case numbers are on the rise, with the number of confirmed COVID-19 cases exceeding 42,000 in Uganda as of May 2021 [4]. While approximately 15\% of COVID-19 patients will experience severe disease requiring oxygen support, and 5\% will develop critical disease [5], 
most sub-Saharan African countries are highly unprepared for a large number of patients. Uganda has less than one hospital bed per 1000 people and only 137 intensive care unit beds in public hospitals for 46 million inhabitants [6]. Consequently, Uganda enforced strict measures to prevent COVID-19, implementing a nationwide lockdown five days before the first case of COVID-19 was detected [2,7]. As reported from a presidential address on 18 March 2020, all public gatherings, institutions, and events were suspended for around two months [7,8]. Apart from the strict lockdown, the Ugandan National COVID-19 strategy [6] also emphasized raising public awareness on risk factors for transmission and promoting infection prevention and control practices to mitigate the spread of COVID-19. Yet, the adherence to rigid infection control and prevention measures is often challenging in resource-limited settings. People in poorer communities often live together in cramped housing conditions with poor access to clean water, making social distancing or frequent handwashing extremely difficult [3].

So far, there is limited insight into knowledge, awareness, and practices (KAP) within sub-Saharan African communities with regard to COVID-19 and applied response strategies. In Uganda, the few existing KAP studies have targeted health workers [9] or medical students [10] and/or were conducted through online assessments [11,12], thus potentially biasing outcomes by neglecting poorer or less educated parts of the population, while mostly featuring only small samples. KAP studies assessing the situation of pregnant women, even though being particularly vulnerable during public health emergencies such as the SARS-CoV-2 pandemic, are even scarcer $[13,14]$. Pregnant women are prone to respiratory pathogens and the development of severe pneumonia due to altered cell-mediated immunity and pulmonary function, and viral pneumonia is assumed to be among the most frequent non-obstetric infectious diseases during pregnancy $[15,16]$. Hence, pregnant women might be more susceptible to COVID-19 than the general population [15]. Apart from a physical risk for maternal health, it has also been suggested that increased psychological stress related to the pandemic might harm pregnant women's health and wellbeing and could also compromise neonatal and infant health by leading to intrauterine growth restrictions or neurodevelopmental disorders [17]. Accordingly, pregnant women require categorization as the key at-risk population in measures focusing on the prevention of SARS-CoV-2 infection [15]. In April 2020, the Uganda Ministry of Health published guidelines for care during pregnancy, delivery, and postnatal care in the context of COVID-19. The guidelines established strategies to mitigate the impact of the pandemic on pregnant women, such as conducting targeted antenatal care (ANC) outreaches, continuation of provision of family planning services, screening pregnant women for intimate partner violence, and screening pregnant women for signs and symptoms of COVID-19, among others [18]. However, there is no evidence if and how these guidelines are implemented in practice.

The goal of our study was to gain insight into knowledge, prevention behavior adherence, generally adapted behavior patterns, and psycho-emotional stress levels in the context of SARS-CoV-2 among pregnant women who experienced lockdown in Fort Portal, Uganda.

\section{Materials and Methods}

We conducted a cross-sectional KAP study among pregnant women accessing ANC services in Fort Portal, Western Uganda. Fort Portal municipality, located in Kabarole District, has a population of about 50,000; $98 \%$ of the households live within $5 \mathrm{~km}$ to the nearest health facility. There are about $48 \%$ women of reproductive age and about $5 \%$ expected pregnancies per year from the total Ugandan population [19]. The governmental recommendation for Ugandan women is to have four ANC visits during their pregnancy; about $40 \%$ of women are covered in the fourth visit [19]. The study sites comprised three health facilities: a private catholic hospital (Virika) and a public referral hospital (Buhinga), both located in Fort Portal town, and a governmental health center (Kibiito) in the rural surroundings of Fort Portal. 
Women were recruited for a larger study on HIV prevention counselling when approaching ANC for the first time in their current pregnancy. Due to the eligibility criteria of the larger study, the cohort did not include HIV-positive women and women in a gestational age above 28 weeks. We included pregnant minors if they were 14 and above ("emancipated minors" [20]) due to their specific relevance regarding vulnerability. Our present study on COVID-19 was conducted among a subset of participants of this larger HIV prevention study. Recruitment and data collection started directly after the first lockdown phase in Uganda in June 2020. For our subset, up to September 2020, we included all women who were recruited for the overarching HIV prevention study, resulting in a sample of 648. Participants were interviewed after their routine ANC visit by trained local study nurses capable of local languages using a structured questionnaire.

Next to sociodemographic information, we assessed economic status by household assets, including radio, fridge, motorbike or car, electricity, tap water, cupboard, TV, cattle, and mosquito net. Each item was given one point upon presence, resulting in a wealth score ranging from 0 to 9 [21,22]. The questionnaire further contained a section on COVID-19, which had been adapted from the WHO-suggested approach to behavioral insights research for COVID-19 [23]. Questions covered knowledge, adherence to preventive behavior, and psycho-emotional stress. The questionnaire also covered general behavioral adaptations in the wake of the pandemic. Scale ends of questions and phrasing of questions are visible in the respective tables (also see Supplementary Material, Table S1 and Table S2).

We created binary relative categories ("higher" versus "lower") for our outcome variables due to the lack of validated scores in the context of COVID-19 at the time of data collection. A higher knowledge status on COVID-19 was defined as: knowing the common symptoms "fever", "cough", "shortness of breath", and the specific symptom "loss of taste and smell" AND knowing the incubation period of 14 days AND knowing that there was (at time of study conduction) no vaccine or treatment for COVID-19. Higher prevention behavior adherence was defined as the person stating to practice all of the following "often": washing their hands, wearing a facemask, using disinfectants, avoid touching their face, keeping $2 \mathrm{~m}$ distance from others, and staying at home in case of symptoms. These items were chosen because they represent the most commonly propagated measures. A higher level of psycho-emotional distress was defined as worrying "a lot" (as opposed to "to some extent/not at all") about all of the following items: own physical health, pregnancy being affected, losing someone beloved, and being unable to pay bills. We combined those items because they represent a mental burden in four different major areas of life in pregnant women (i.e., general health, pregnancy, family, and finances).

The underlying sample size of 648 pregnant women is solely based on the abovedescribed subset of participants in the larger HIV prevention study from June until September 2020, so that no formal sample size calculation was conducted in advance. Therefore, all following calculations are to be understood descriptively. Categorical outcomes are described by absolute and relative numbers; ordinal and metric outcomes are presented by median and range or mean and standard deviation, respectively (Table 1). Factors associated with a lower knowledge level about COVID-19, influencing factors on lower prevention behavior adherence and factors associated with higher psycho-emotional stress level were additionally reported by odds ratios (OR) and 95\% confidence intervals (95\%CI) as well as adjusted odds ratios (AOR) with $95 \% \mathrm{CI}$. Reference groups, as well as covariables for the adjusted models, are shown in the respective Tables $2-4$. Confidence intervals were not adjusted for multiple testing, and p-values are not reported due to the exploratory study design. The numbers of missing values per analysis were relatively low, so no imputation was conducted (explicit numbers of missing values are reported in the corresponding tables). The calculations were performed with $\mathrm{R}$ version 3.6.1, and the package "oddsratio" was used. 
Table 1. Sociodemographic characteristics of the women and their partners.

\begin{tabular}{|c|c|}
\hline Total $n=648$ & $\mathrm{~N}(\%)$ \\
\hline Age $(n=647)$ & 25.5 (5.8) (mean, standard deviation) \\
\hline \multicolumn{2}{|l|}{ Marital Status $(n=648)$} \\
\hline Married & $525(81.0)$ \\
\hline Couple & $29(4.5)$ \\
\hline Single & $91(14.0)$ \\
\hline Divorced & $3(0.5)$ \\
\hline \multicolumn{2}{|l|}{ Health Facility $(n=648)$} \\
\hline Buhinga (urban, public) & $322(49.7)$ \\
\hline Virika (urban, private) & $141(21.8)$ \\
\hline Kibiito (rural, public) & $185(28.6)$ \\
\hline \multicolumn{2}{|l|}{ Completed Education $(n=646)$} \\
\hline None & $25(3.9)$ \\
\hline Primary & $305(47.2)$ \\
\hline Secondary & $232(35.9)$ \\
\hline Tertiary & $84(13.0)$ \\
\hline \multicolumn{2}{|l|}{ Occupation $(n=639)$} \\
\hline Farmer & $246(38.5)$ \\
\hline Trader/self-employed (unspecified) & $122(19.1)$ \\
\hline Homemaker & $118(18.5)$ \\
\hline Hair dresser & $27(4.2)$ \\
\hline Teacher & $20(3.1)$ \\
\hline Tailor & $20(3.1)$ \\
\hline Other & $86(13.5)$ \\
\hline \multicolumn{2}{|l|}{ Religion $(n=647)$} \\
\hline Christian & $604(93.4)$ \\
\hline Muslim & $35(5.4)$ \\
\hline Other & $8(1.2)$ \\
\hline Number of children living in household $(n=644)$ & $1(0 ; 7)$ (median, range) \\
\hline \multicolumn{2}{|l|}{ Wealth score $[21,22]$} \\
\hline Lower $(0-4)$ & $287(44.3)$ \\
\hline Higher (5-9) & $361(55.7)$ \\
\hline \multicolumn{2}{|l|}{ Partner occupation $(n=648)$} \\
\hline Farmer & $172(26.5)$ \\
\hline Trader/self-employed (unspecified) & $133(20.5)$ \\
\hline Workmen (e.g., builder, engineer, mechanic) & $106(16.3)$ \\
\hline Driver (e.g., taxi, motorbike taxi, truck) & $88(13.6)$ \\
\hline Civil service, armed forces & $51(7.9)$ \\
\hline Other & $98(15.2)$ \\
\hline \multicolumn{2}{|l|}{ Financially dependent on partner $(n=648)$} \\
\hline Completely & $226(34.9)$ \\
\hline For the most part & $222(34.3)$ \\
\hline For some part & $183(28.2)$ \\
\hline Not at all & $17(2.6)$ \\
\hline \multicolumn{2}{|l|}{$\begin{array}{l}\text { Physical violence and/or other partner harassment? } \\
\qquad(n=647)\end{array}$} \\
\hline Yes & $59(9.1)$ \\
\hline No & $588(90.9)$ \\
\hline
\end{tabular}


Table 2. Factors associated with lower knowledge level calculated by logistic regression $(n=635)$.

\begin{tabular}{|c|c|c|c|}
\hline Variable & $\begin{array}{c}\text { Lower Knowledge Level } \\
n=427(67.24 \%) \\
\text { N (\%) }\end{array}$ & OR $(95 \% \mathrm{CI})$ & AOR $(95 \% \mathrm{CI})$ \\
\hline \multicolumn{4}{|l|}{ Age groups } \\
\hline$<21$ & $92(69.70)$ & reference & reference \\
\hline $21-30$ & $254(67.02)$ & $0.88(0.57 ; 1.35)$ & $0.85(0.53 ; 1.35)$ \\
\hline $31-40$ & $76(65.55)$ & $0.83(0.48 ; 1.41)$ & $0.80(0.45 ; 1.42)$ \\
\hline$>40$ & $5(62.50)$ & $0.73(0.17 ; 3.67)$ & $0.76(0.17 ; 3.99)$ \\
\hline \multicolumn{4}{|l|}{ Marital status } \\
\hline Married or couple & $362(66.06)$ & reference & reference \\
\hline Single or divorced & $65(74.71)$ & $1.52(0.92 ; 2.60)$ & $1.74(1.01 ; 3.07)$ \\
\hline \multicolumn{4}{|l|}{ Education } \\
\hline None & $17(68.00)$ & reference & reference \\
\hline Primary & $201(66.56)$ & $0.94(0.37 ; 2.18)$ & $0.74(0.29 ; 1.78)$ \\
\hline Secondary & $146(64.89)$ & $0.87(0.34 ; 2.05)$ & $0.79(0.29 ; 1.98)$ \\
\hline Tertiary & $63(75.90)$ & $1.48(0.54 ; 3.88)$ & $1.24(0.39 ; 3.76)$ \\
\hline \multicolumn{4}{|l|}{ Occupation } \\
\hline Not formally employed & $329(68.12)$ & reference & reference \\
\hline Formally employed & $98(64.47)$ & $0.85(0.58 ; 1.25)$ & $0.62(0.38 ; 1.00)$ \\
\hline \multicolumn{4}{|l|}{ Wealth score } \\
\hline $0-4$ & $189(67.50)$ & reference & reference \\
\hline $5-9$ & $238(67.04)$ & $0.98(0.70 ; 1.37)$ & $0.95(0.64 ; 1.40)$ \\
\hline \multicolumn{4}{|l|}{ Source of knowledge } \\
\hline TV or Radio & $395(66.16)$ & reference & reference \\
\hline Social Media or Internet & $4(100)$ & $4.09(0.74 ; 76.16)$ & $4.12(0.71 ; 78.03)$ \\
\hline Community, other people & $17(85.00)$ & $2.90(0.96 ; 12.52)$ & $2.07(0.65 ; 9.20)$ \\
\hline Church or hospital & $8(88.89)$ & - & - \\
\hline \multicolumn{4}{|l|}{ Health Facility } \\
\hline Buhinga (urban, public) & $196(62.82)$ & reference & reference \\
\hline Virika (urban, private) & $115(82.14)$ & $2.72(1.69 ; 4.52)$ & $2.63(1.57 ; 4.53)$ \\
\hline Kibiito (rural, public) & $116(63.39)$ & $1.03(0.70 ; 1.50)$ & $1.02(0.67 ; 1.56)$ \\
\hline
\end{tabular}

OR—odds ratio; AOR—Adjusted odds ratio with all variables included in this table as covariables; $\mathrm{CI}-$ Confidence interval. 
Table 3. Factors associated with lower prevention behavior adherence calculated by logistic regression $(n=634)$.

\begin{tabular}{|c|c|c|c|}
\hline Variable & $\begin{array}{l}\text { Lower Prevention Behavior Adherence } \\
\qquad \begin{array}{c}n=52(88.64 \%) \\
\text { N }(\%)\end{array}\end{array}$ & OR (95\% CI) & AOR $(95 \% \mathrm{CI})$ \\
\hline \multicolumn{4}{|l|}{ Age groups } \\
\hline$<21$ & $125(95.42)$ & reference & \\
\hline $21-30$ & $331(87.34)$ & $0.33(0.12 ; 0.74)$ & $0.50(0.18 ; 1.21)$ \\
\hline $31-40$ & $99(85.34)$ & $0.28(0.10 ; 0.70)$ & $0.44(0.15 ; 1.19)$ \\
\hline$>40$ & $7(87.50)$ & $0.34(0.05 ; 6.79)$ & $0.56(0.07 ; 11.92)$ \\
\hline \multicolumn{4}{|l|}{ Marital status } \\
\hline Married or couple & $481(87.77)$ & reference & \\
\hline Single, widow, divorced & $81(94.19)$ & $2.26(0.97 ; 6.59)$ & $1.58(0.62 ; 4.88)$ \\
\hline \multicolumn{4}{|l|}{ Education } \\
\hline None & $22(88.00)$ & reference & \\
\hline Primary & 277 (92.03) & $1.57(0.36 ; 4.98)$ & $1.28(0.27 ; 4.40)$ \\
\hline Secondary & $199(88.44)$ & $1.04(0.24 ; 3.29)$ & $0.83(0.17 ; 3.12)$ \\
\hline Tertiary & $64(77.11)$ & $0.46(0.10 ; 1.52)$ & $0.68(0.12 ; 3.15)$ \\
\hline \multicolumn{4}{|l|}{ Occupation } \\
\hline Not formally employed & $431(89.42)$ & reference & \\
\hline Formally employed & $131(86.18)$ & $0.74(0.43 ; 1.30)$ & $0.92(0.47 ; 1.89)$ \\
\hline \multicolumn{4}{|l|}{ Wealth score $[21,22]$} \\
\hline $0-4$ & $257(92.11)$ & reference & \\
\hline $5-9$ & $305(85.02)$ & $0.52(0.30 ; 0.88)$ & $0.54(0.28 ; 1.02)$ \\
\hline \multicolumn{4}{|l|}{ COVID-19 knowledge } \\
\hline Higher & $184(88.89)$ & reference & \\
\hline Lower & $378(88.52)$ & $0.96(0.56 ; 1.61)$ & $1.15(0.64 ; 2.03)$ \\
\hline \multicolumn{4}{|l|}{ Emotional stress level } \\
\hline Higher & $214(84.58)$ & reference & \\
\hline Lower & $348(91.34)$ & $1.92(1.17 ; 3.16)$ & $1.19(0.66 ; 2.12)$ \\
\hline \multicolumn{4}{|l|}{ Health Facility } \\
\hline Buhinga (urban, public) & $299(95.83)$ & reference & \\
\hline Virika (urban, private) & $107(76.43)$ & $0.14(0.07 ; 0.27)$ & $0.18(0.08 ; 0.36)$ \\
\hline Kibiito (rural, public) & $156(85.71)$ & $0.26(0.13 ; 0.51)$ & $0.17(0.08 ; 0.36)$ \\
\hline
\end{tabular}

OR—odds ratio; AOR—Adjusted odds ratio with all variables included in this table as covariables; CI—Confidence interval. 
Table 4. Factors associated with higher psycho-emotional stress level calculated by logistic regression $(n=630)$.

\begin{tabular}{|c|c|c|c|}
\hline Variable & $\begin{array}{l}\text { Higher Psycho-Emotional Stress Level } \\
\qquad n=251(39.84 \%) \\
\mathrm{N}(\%)\end{array}$ & OR (95\% CI) & AOR $(95 \% \mathrm{CI})$ \\
\hline \multicolumn{4}{|l|}{ Age groups } \\
\hline$<21$ & $30(22.90)$ & reference & \\
\hline $21-30$ & $177(46.95)$ & $2.98(1.91 ; 4.76)$ & $1.97(1.18 ; 3.35)$ \\
\hline $31-40$ & $42(36.52)$ & $1.94(1.11 ; 3.40)$ & $1.81(0.92 ; 3.59)$ \\
\hline$>40$ & $2(28.57)$ & $1.35(0.19 ; 6.60)$ & $2.05(0.26 ; 11.78)$ \\
\hline \multicolumn{4}{|l|}{ Marital status } \\
\hline Married/couple & $232(42.65)$ & reference & \\
\hline Single/divorced & $19(22.09)$ & $0.38(0.22 ; 0.64)$ & $0.42(0.22 ; 0.77)$ \\
\hline \multicolumn{4}{|l|}{ Education } \\
\hline None & $5(20.83)$ & reference & \\
\hline Primary & $87(29.00)$ & $1.55(0.60 ; 4.80)$ & $1.67(0.62 ; 5.34)$ \\
\hline Secondary & $96(43.05)$ & $2.87(1.11 ; 8.91)$ & $2.70(0.95 ; 8.82)$ \\
\hline Tertiary & $63(75.90)$ & $11.97(4.22 ; 39.98)$ & $6.80(2.04 ; 25.80)$ \\
\hline \multicolumn{4}{|l|}{ Occupation } \\
\hline Not formally employed & $167(34.79)$ & reference & \\
\hline Formally employed & $84(56.00)$ & $2.39(1.65 ; 3.47)$ & $1.38(0.83 ; 2.27)$ \\
\hline \multicolumn{4}{|l|}{ Wealth score } \\
\hline $0-4$ & $91(32.73)$ & reference & \\
\hline $5-9$ & $160(45.45)$ & $1.71(1.24 ; 2.38)$ & $1.03(0.68 ; 1.55)$ \\
\hline \multicolumn{4}{|l|}{$\begin{array}{l}\text { Number of children living at } \\
\text { home }\end{array}$} \\
\hline $0-1$ & $153(43.97)$ & reference & \\
\hline$\geq 2$ & $98(34.75)$ & $0.68(0.49 ; 0.94)$ & $0.64(0.42 ; 0.95)$ \\
\hline \multicolumn{4}{|l|}{$\begin{array}{l}\text { Financial dependence on } \\
\text { partner }\end{array}$} \\
\hline Not at all & $4(26.67)$ & reference & \\
\hline For some part & $80(45.71)$ & $2.32(0.76 ; 8.61)$ & $1.55(0.44 ; 6.56)$ \\
\hline For the most part & $92(42.40)$ & $2.02(0.67 ; 7.49)$ & $1.49(0.42 ; 6.32)$ \\
\hline Completely & $75(33.63)$ & $1.39(0.46 ; 5.16)$ & $1.10(0.31 ; 4.67)$ \\
\hline \multicolumn{4}{|l|}{$\begin{array}{l}\text { Emotionally or physically } \\
\text { threatened by partner }\end{array}$} \\
\hline No & $229(40.03)$ & reference & \\
\hline Yes & $22(37.93)$ & $0.92(0.52 ; 1.58)$ & $1.63(0.85 ; 3.09)$ \\
\hline \multicolumn{4}{|l|}{ COVID-19 Knowledge } \\
\hline High & $104(50.00)$ & reference & \\
\hline Low & $147(34.83)$ & $0.54(0.38 ; 0.75)$ & $0.40(0.27 ; 0.58)$ \\
\hline \multicolumn{4}{|l|}{ Health Facility } \\
\hline Buhinga (urban, public) & $110(35.60)$ & reference & \\
\hline Virika (urban, private) & $85(60.71)$ & $2.80(1.86 ; 4.24)$ & $2.82(1.73 ; 4.65)$ \\
\hline Kibiito (rural, public) & $56(30.94)$ & $0.81(0.55 ; 1.20)$ & $1.28(0.81 ; 2.03)$ \\
\hline
\end{tabular}

OR—odds ratio; AOR—Adjusted odds ratio with all variables included in this table as covariables; $\mathrm{CI} —$ Confidence interval.

\section{Results}

We interviewed 648 pregnant women who visited one of the three participating health facilities for their first ANC visit. Sociodemographic characteristics are displayed in Table 1. Key baseline characteristics of our sample, such as age, marital status, education, or occupation, were largely corresponding with another sample of pregnant women in 
Western Uganda [22], implying comparability of our sample for pregnant women in this region.

\subsection{Knowledge of SARS-CoV-2}

All participants heard of SARS-CoV-2 in some form, mostly by radio, TV, or through other people in the community. Symptoms of fever $(603 ; 93.2 \%)$, cough $(605 ; 93.4 \%)$, and rhinorrhea (588; $91.0 \%)$ were most commonly known, followed by shortness of breath (581; $89.7 \%)$, headache (507: 78.5\%), and sore throat (504; 77.8\%). Fewer women knew that loss of taste and smell $(331 ; 51.2 \%)$ or diarrhea $(152 ; 23.5 \%)$ could also be the symptoms. 545 $(84.2 \%)$ of the women correctly stated the incubation period of 14 days (Supplementary Material Table S1, Figure S1).

According to our definition, 208 (32.8\%) participants showed a higher knowledge of COVID-19, while $427(67.2 \%)$ had a lower knowledge level. The clientele at the private Virika hospital displayed lower knowledge compared to the public Buhinga hospital. Women who were single or divorced tended to have lower knowledge than coupled women in multivariable analysis (AOR 1.74; 1.01-3.07). Within this model, we could not identify other factors linked with knowledge level (Table 2).

\subsection{Hygiene Behavior and General Behavioral Adaptations}

Wearing facemasks, coughing/sneezing etiquette, and washing hands were practiced “often" by $60.3 \%$ (391), 55.4\% (358), and 55.9\% (361), respectively. Only 225 out of 648 women $(34.7 \%)$ reported to often keep $2 \mathrm{~m}$ physical distance to others. (Supplementary Material, Table S1) Altogether, 72 (11.4\%) women fulfilled our definition of higher adherence to hygiene and preventive behavior, while $562(88.6 \%)$ showed lower adherence (Table 3). Compared to the age group $<21$ years, women between the age of 21 and 30 years and between 31 and 40 years were less likely to show lower adherence to prevention behavior, similar to women with a higher wealth score compared to women with a lower wealth score. The only difference with a stable association after adjusting was the attended health institution, with clients at the private (Virika) and the rural (Kibiito) health institutions showing lower odds of lower adherence compared to clients of the rural public Buhinga hospital.

As to COVID-19 related behavioral adaptations, $92.4 \%$ (599) stated they were avoiding people from other geographic regions like China or Europe, $89.7 \%$ (581) bought personal protective equipment, $83.5 \%$ (540) stocked up their homes with food supplies, $51.9 \%$ (334) reported that they had asked family and friends to refrain from visiting, and $48.4 \%$ (313) exercised less than before. The majority stated it would be unlikely that due to the pandemic, they would eat unhealthier food or drink more alcohol. Just 13.5\% (87 women) stated they had difficulties receiving healthcare or ANC services. (Supplementary Material Table S2)

\subsection{Psycho-Emotional Stress}

The extent of various emotional concerns is summarized in Figure 1 and Supplementary Material Table S2.

We identified $251(39.8 \%)$ women with a higher overall psycho-emotional stress level as per our definition. The age groups $21-30$ and $31-40$ years had increased odds for higher psycho-emotional stress as compared to women below 21 years. This could be confirmed for the age group 21-30 years compared to $<21$ years in multivariable analysis (AOR 1.97, 1.18-3.35). (Table 4) Being single or divorced was associated with lower odds for psycho-emotional stress than being married or coupled (AOR 0.42; 0.22-0.77). The odds for higher psycho-emotional stress increased with educational level: compared to women with no education, women with tertiary education had a six-fold increased risk for higher psycho-emotional stress (AOR 6.80; 2.04-25.80). Women with two or more children were less likely to experience a high level of psycho-emotional stress (AOR 0.64; 0.42-0.95). Women with a low level of COVID-19 related knowledge were less likely to 
have a high emotional workload (AOR 0.40; 0.27-0.58). In women who were clients at Virika hospital, the risk for higher psycho-emotional stress was about twice as high as in Buhinga (AOR 2.82; 1.73-4.65) (Table 4).

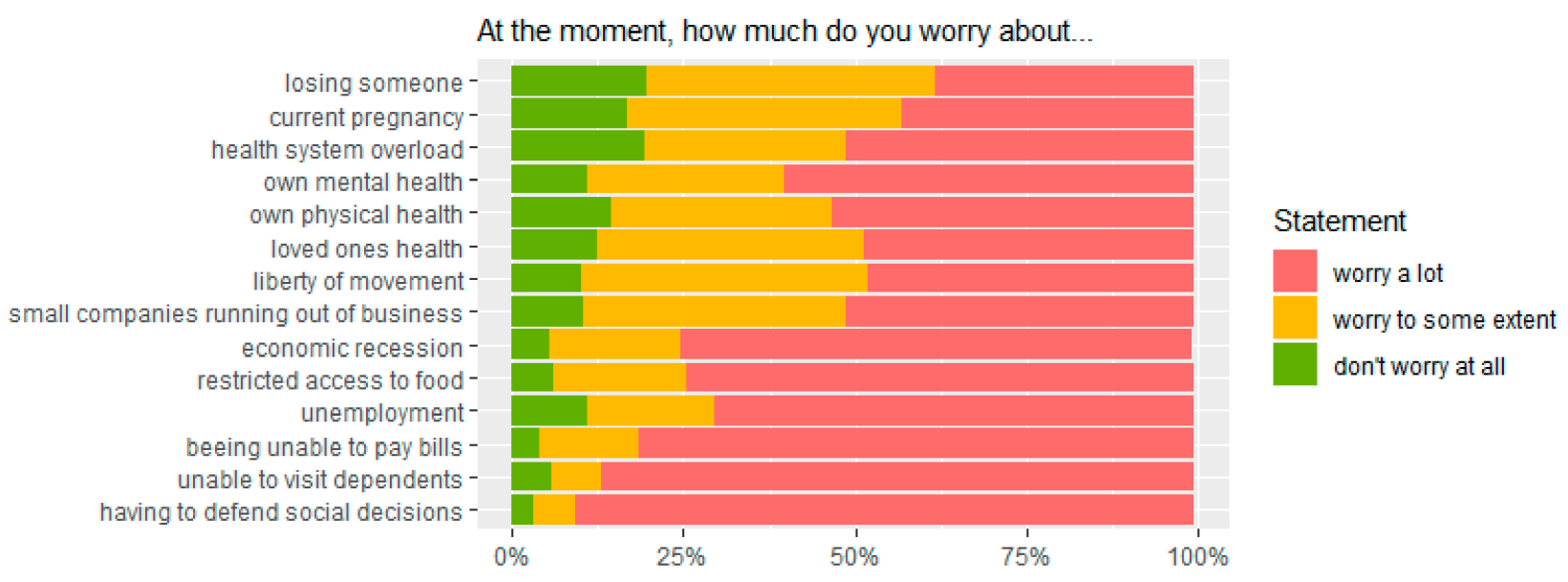

Figure 1. Statements on psycho-emotional stress during the pandemic.

\section{Discussion}

Our study represents one of the first large-scale assessments of pregnant women's knowledge, behavior, and emotional wellbeing in the context of SARS-CoV-2 and the COVID-19 response in sub-Saharan Africa in 2020. In summary, we showed that in Fort Portal Region, pregnant women from all different socioeconomic backgrounds were overall informed and knowledgeable about the COVID-19 pandemic. However, self-reported compliance with hygiene behavior measures was relatively low, and a majority of the pregnant women was clearly burdened by worries and fears related to the pandemic.

One in three women demonstrated a higher knowledge level on SARS-CoV-2. The majority of the participants mentioned radio as their main information source. Throughout different health contexts in sub-Saharan Africa, the use of radio-based information promoted by official sources, reinforcing the region's narrative tradition, has proven to be a highly accessible and effective medium for health information [24]. In our study population, knowledge was not dependent on education, occupation, and wealth status, which is encouraging in terms of low-threshold accessibility and quality of information campaigns on a local level.

While our cohort was reasonably adherent to single hygiene measures such as mask wearing or hand washing, only one in three women kept a physical distance of $2 \mathrm{~m}$ most of the time. This measure might be plainly impossible to apply in densely populated conditions, when working in informal sectors, or depending on local markets for alimentation. Juxtaposing official hygiene recommendations with their daily practicability in a particular setting is an important part of local public health decision making, as also pointed out in studies from Nigeria, South Africa, and India [25-27]. In this context, the reflexive adoption of Western countries' COVID-19 responses by African leaders can be viewed as counterproductive, and measures like physical distancing might appear elitist and unrealistic in many resource-limited settings [27,28]. Wasdani and Prasad (2020) particularly note the economic implications involved in the ability to adhere to such measures, suggesting respective governmental support like interim subsistence allowances for women in informal jobs where physical distancing is impossible. This might be especially important for women, who are rarely formally employed in such settings.

Only one in ten women complied with our definition of higher behavior adherence most of the time. Clients from the urban public Buhinga hospital were less likely to show prevention behavior adherence compared to the private hospital and the rural public facility. The latter is in contradiction with other studies, where rural populations were significantly 
less compliant with COVID-19-related behavior changes [28,29]. We suspect that facility size might also play a role, with smaller rural health centers possibly featuring stronger personal client-staff connections leading to higher client commitment compared to large urban referral institutions, where services tend to be more impersonal, and client-staff communication might be less beneficial [30]. At the same time, health institutions only represent one of many players in promoting hygiene measures and behaviors, and our finding might as well point to an underlying unidentified confounder with regard to the Buhinga clientele. The same applies to the finding that in the catholic hospital, clients were less knowledgeable but more prone to the higher psycho-emotional stress level. Either way, identifying clientele differences across varying facilities might be valuable, as targeting entire healthcare settings for hygiene or knowledge campaigns could entail pragmatic and economical implementation advantages compared to identifying individual clients in need.

We found a large degree of general behavior adaptation to the pandemic situation among pregnant women, including stocking up food and protective equipment or alteration of social habits. Yet alarmingly, misleading COVID-19 information might have spiraled up xenophobic tendencies with our sample reporting to avoid people who, for example, look Chinese, especially considering that in countries like Uganda, Chinese laborers are ubiquitous, and there have been tensions and propensities of "othering" in the past years [31]. It is of utmost importance, in Uganda as anywhere else, that such tendencies are counteracted with comprehensive public information campaigns, educating people about tangible risks for infection in their living environment rather than perpetuating xenophobic prejudices.

One in eight women did not receive healthcare or ANC at any point due to the pandemic. Although this means that the majority of women did not have problems receiving care, it still is a concerning rate given the importance of healthcare during pregnancy and the catastrophic impact obstetric service disruption can have on maternal and neonatal health [32].

A large part of the women reported psychosocial impact and worries, with $38 \%$ of the women showing a particularly high psycho-emotional stress level. Although comparability might be limited, this percentage exceeds pre-pandemic findings, such as a large metaanalysis of 52 studies which identified an overall pooled prevalence of $23 \%$ for self-reported anxiety symptoms in pregnancy [33], or a study in South Africa, where $16 \%$ of pregnant women showed a high stress level. [34] From the time of the pandemic, $21 \%$ of pregnant women in Wuhan, China, showed signs of anxiety [14]. The high psycho-emotional stress level in our cohort is worrisome, given that antenatal stress and anxiety have significant implications for obstetric outcomes and pediatric health impairment, including increased risk for premature birth, fetal growth restriction, and obstetric complications [33-35]. Women with tertiary education and women with higher knowledge of the pandemic were at increased risk for psycho-emotional stress in our setting, which was similar to findings from Italy [36]. This may point to a higher awareness of overall health and social risks through the pandemic in the better-educated and -informed part of the population. While providing realistic information on the pandemic is crucial, it should be kept in mind that it might also cause serious anxieties and that vulnerable groups of the population should not be left alone with distressing knowledge. Telephone hotlines or focal points where further advice can be obtained could be worthwhile options to compensate for individual worries arising in the wake of information campaigns.

Women in their twenties, women in a relationship or marriage, and women who were a first-time parent or a parent of only one child were also more likely to experience higher psycho-emotional stress levels. While primiparity has been associated with higher antenatal stress levels [35,37], the other factors are somewhat surprising, as there has been evidence that pregnant women in more precarious situations, i.e., being very young, single, or providing for several children, are more affected by psycho-emotional stress [35,38,39]. Yet, being in a partnership does not always equal receiving support, as pointed out by Bilszta et al., who found antenatal depression less prevalent in unpartnered mothers 
compared to mothers with unsupportive partners [40]. A large meta-analysis by Biaggi et al. [35] concluded that not only marital status should be considered, but also couple relationship quality, and against this background, being a single mother could be better for antenatal mental health than being in a difficult partnership.

The strength of our study is that it represents a comprehensive assessment of COVID19 related repercussions among a large sample of pregnant women in a low-income country and that we did not limit the study population to women able to access an online questionnaire, avoiding an omnipresent selection bias in KAP research during the COVID-19 pandemic. As a limitation, we cannot exclude some degree of desirability or reporting bias concerning health-related behaviors. Questionnaires based on self-reported behavior are potentially prone to over- or under-reporting, and our results must be seen in light of this possible bias. However, the study nurses were trained to interview in a non-judgmental style and probe answers in order to avoid biased results as much as possible. Also, we used a self-adjusted questionnaire, which narrows possibilities for comparison with other settings. More specific questions pertaining to pregnancy-related fears could have been informative to develop support interventions. However, we believe that in light of lacking respective data, the broad range of our findings will contribute to better understanding pregnant women's situation during an ongoing pandemic.

\section{Conclusions}

In conclusion, although a certain level of knowledge on the pandemic was rather widespread, pregnant women were often unable to comply with hygiene behavior measures in their daily lives, and fears and worries were ubiquitous. Prevention campaigns for COVID-19 should clearly relate to the everyday realities of women in a given regional setting, realistically considering which measures are practicable to apply and offering solutions for those that are not. This should include governmental subsistence support, particularly for women in informal sector jobs, to enable them to follow pandemic measures despite precarious living conditions. Apart from that, the emotional state of pregnant women should represent a focus of outreaching community healthcare in an exceptional time such as the SARS-CoV-2 pandemic to avoid adverse consequences in maternal and neonatal health.

Supplementary Materials: The following are available online at https:/ /www.mdpi.com/article/10 .3390/ijerph18157817/s1, Figure S1: SARS-CoV-2 related knowledge in pregnant women, Table S1: Descriptive overview of knowledge on COVID-19 and prevention measures, Table S2: Descriptive overview of behavioral aspects and psychosocial impact of the pandemic.

Author Contributions: Conceptualization, S.T. and J.R.; methodology, S.T., L.H., C.H. and J.R.; formal analysis, L.H. and C.H.; investigation, A.K. and J.R.; data curation, L.H., C.H. and S.T.; writing—original draft preparation, S.T.; writing—review and editing, A.K., L.H., C.H., S.N.K. and J.R.; visualization, L.H.; supervision, J.R., S.N.K. and S.T.; project administration, A.K., S.N.K. and J.R.; funding acquisition, S.T. All authors have read and agreed to the published version of the manuscript.

Funding: This research was conducted as a substudy of a project funded by the H.W. \& J. Hector Foundation, Germany.

Institutional Review Board Statement: The study was conducted according to the guidelines of the Declaration of Helsinki and approved by the Uganda National Council for Science and Technology (Ethical approval UNCST HS 2766) and by the Ethics Committee of Charité-Universitätsmedizin Berlin (EA2/212/20).

Informed Consent Statement: Informed consent was obtained from all subjects involved in the study.

Data Availability Statement: The data presented in this study and the $\mathrm{R}$ code are available on request from the corresponding author. The data are not publicly available due to the possible identifiability of participants and data containing sensitive information, as this substudy was conducted in the frame of an HIV-related research project. 
Acknowledgments: The authors thank the study nurses and involved staff at the three healthcare facilities.

Conflicts of Interest: The authors declare no conflict of interest. The funders had no role in the design of the study, in the collection, analyses, or interpretation of data, in the writing of the manuscript, or in the decision to publish the results.

\section{References}

1. WHO. Addendum to Fact Sheet 15 on National Implementation Measures for the International Health Regulations 2005: COVID-19 as a Public Health Emergency of International Concern (PHEIC) under the IHR. 2020. Available online: https: // extranet.who.int/sph/sites/default/ files / document-library/document/FS15A_IHR_COVID19_EN_MAY_2020.pdf (accessed on 5 May 2021).

2. Kapata, N.; Ihekweazu, C.; Ntoumi, F.; Raji, T.; Chanda-Kapata, P.; Mwaba, P.; Mukonka, V.; Bates, M.; Tembo, J.; Corman, V.; et al. Is Africa prepared for tackling the COVID-19 (SARS-CoV-2) epidemic. Lessons from past outbreaks, ongoing pan-African public health efforts, and implications for the future. Int. J. Infect. Dis. 2020, 93, 233-236. [CrossRef]

3. El-Sadr, W.M.; Justman, J. Africa in the Path of Covid-19. N. Engl. J. Med. 2020, 383, e11. [CrossRef] [PubMed]

4. Worldometer. COVID-19 Coronavirus Pandemic. Dover, Delaware: Worldometers.info. 2020. Available online: www. worldometers.info/coronavirus/ (accessed on 5 May 2021).

5. WHO. Clinical Management of COVID-19. Interim Guidance. 27 May 2020. Available online: https://apps.who.int/iris/handle/ 10665/332196 (accessed on 5 May 2021).

6. MoH Uganda, 2020. COVID-19 Preparedness and Response Plan. March 2020- June 2021. Available online: https://covid19. gou.go.ug/uploads/document_repository/authors/ministry_of_health/document/COVID19_PreparednessResponse_Plan_ Signed_Vers_July20201.pdf (accessed on 5 May 2021).

7. Mukaama, I.; Observer Research Foundation. The Expected Outcomes of the post-COVID19 Lockdown in Uganda. 4 June 2020. Available online: https:/ / www.orfonline.org/expert-speak/the-expected-outcomes-of-the-post-COVID-19-lock-downin-uganda-67299/ (accessed on 5 May 2021).

8. Museveni, Y.K. Address by H.E. Yoweri Museveni President of the Republic of Uganda to the Nation on the Coronavirus (COVID-19) Guidelines on the Preventive Measures 18 March 2020 State House- Entebbe. Available online: https: / kampala. diplo.de/blob/2315822/0468d91d79744d29cf6f2e8ce200da0d/corona-address-to-the-nation-data.pdf (accessed on 5 May 2021).

9. Olum, R.; Chekwech, G.; Wekha, G.; Nassozi, D.R.; Bongomin, F. Coronavirus Disease-2019: Knowledge, Attitude, and Practices of Health Care Workers at Makerere University Teaching Hospitals, Uganda. Front. Public Health 2020, 8, 181. [CrossRef] [PubMed]

10. Olum, R.; Kajjimu, J.; Kanyike, A.M.; Chekwech, G.; Wekha, G.; Nassozi, D.R.; Kemigisa, J.; Mulyamboga, P.; Muhoozi, O.K.; Nsenga, L.; et al. Perspective of Medical Students on the COVID-19 Pandemic: Survey of Nine Medical Schools in Uganda. JMIR Public Health Surveill. 2020, 6, e19847. [CrossRef] [PubMed]

11. Kasozi, K.I.; MacLeod, E.; Ssempijja, F.; Mahero, M.W.; Matama, K.; Musoke, G.H.; Bardosh, K.; Ssebuufu, R.; Wakoko-Studstil, F.; Echoru, I.; et al. Misconceptions on COVID-19 Risk Among Ugandan Men: Results from a Rapid Exploratory Survey, April 2020. Front. Public Health 2020, 8, 416. [CrossRef] [PubMed]

12. Ssebuufu, R.; Sikakulya, F.K.; Mambo, S.B.; Wasingya, L.; Nganza, S.K.; Ibrahim, B.; Kyamanywa, P. Knowledge, Attitude, and Self-Reported Practice Toward Measures for Prevention of the Spread of COVID-19 Among Ugandans: A Nationwide Online Cross-Sectional Survey. Front. Public Health 2020, 8, 618731. [CrossRef]

13. Nwafor, J.I.; Aniukwu, J.K.; Anozie, B.O.; Ikeotuonye, A.C. Knowledge and practice of preventive measures against COVID-19 infection among pregnant women in a low-resource African setting. medRxiv 2020. [CrossRef]

14. Ding, W.; Lu, J.; Zhou, Y.; Wei, W.; Zhou, Z.; Chen, M. Knowledge, attitudes, practices, and influencing factors of anxiety among pregnant women in Wuhan during the outbreak of COVID-19: A cross-sectional study. BMC Pregnancy Childbirth 2021, 21, 1-9. [CrossRef] [PubMed]

15. Qiao, J. What are the risks of COVID-19 infection in pregnant women? Lancet 2020, 395, 760-762. [CrossRef]

16. Schwartz, D.A.; Graham, A.L. Potential Maternal and Infant Outcomes from Coronavirus 2019-nCoV (SARS-CoV-2) Infecting Pregnant Women: Lessons from SARS, MERS, and Other Human Coronavirus Infections. Viruses 2020, 12, 194. [CrossRef]

17. Abdoli, A.; Falahi, S.; Kenarkoohi, A.; Shams, M.; Mir, H.; Jahromi, M.A.M. The COVID-19 pandemic, psychological stress during pregnancy, and risk of neurodevelopmental disorders in offspring: A neglected consequence. J. Psychosom. Obstet. Gynecol. 2020, 41, 247-248. [CrossRef]

18. Uganda Ministry of Health. Guidance on Continuity of Essential Health Services during the COVID-19 Outbreak. April 2020. Available online: https://tciurbanhealth.org/wp-content/uploads/2020/05/MOH-GUIDANCE-ON-BUSINESS-CONTINUITY000.docx3_.pdf (accessed on 16 July 2021).

19. Uganda Ministry of Health. Annual Health Sector Performance Report. Financial Year 2019/2020. Available online: http:// library.health.go.ug/publications / performance-management/annual-health-sector-performance-report-financial-year-201920 (accessed on 16 July 2021). 
20. Uganda National Council for Science and Technology. National Guidelines for Research involving Humans as Re-search Participants. Kampala, Uganda. 2014. Available online: http://mesau.mak.ac.ug/sites/default/files/Human\%20Subjects\%20 Protection\%20Guidelines\%20July\%202014_0.pdf (accessed on 11 May 2021).

21. Schnack, A.; Rempis, E.; Decker, S.; Braun, V.; Rubaihayo, J.; Busingye, P.; Tumwesigye, N.M.; Harms, G.; Theuring, S. Prevention of Mother-to-Child Transmission of HIV in Option B+ Era: Uptake and Adherence During Pregnancy in Western Uganda. AIDS Patient Care STDs 2016, 30, 110-118. [CrossRef]

22. Schumann, H.; Rubagumya, K.; Rubaihayo, J.; Harms, G.; Wanyenze, R.K.; Theuring, S. The incidence of HIV and associated risk factors among pregnant women in Kabarole District, Uganda. PLoS ONE 2020, 15, e0234174. [CrossRef]

23. World Health Organisation Regional Office for Europe. Survey Tool and Guidance: Rapid, Simple, Flexible Behavioural Insights on COVID-19. Monitoring Knowledge, Risk Perceptions, Preventive Behaviours and Trust to Inform Pandemic Outbreak Response. Copenhagen, Denmark, 2020. Available online: https://www.psycharchives.org/bitstream/20.500.12034/2392/8/ Guidance\%20and\%20protocol.BI\%20for\%20COVID-19_160420.pdf (accessed on 12 May 2021).

24. Schroeder, K. Radio as a Tool of Health Education: What Makes for an Effective HIV/AIDS Radio Campaign in Sub-Saharan Africa? Intersect 2016, 9, 3.

25. Gibson, L.; Rush, D. Novel Coronavirus in Cape Town Informal Settlements: Feasibility of Using Informal Dwelling Outlines to Identify High Risk Areas for COVID-19 Transmission from A Social Distancing Perspective. JMIR Public Health Surveill 2020, 6, e18844. [CrossRef] [PubMed]

26. Iwuoha, V.C.; Aniche, E.T. Covid-19 lockdown and physical distancing policies are elitist: Towards an indigenous (Afro-centred) approach to containing the pandemic in sub-urban slums in Nigeria. Local Environ. 2020, 25, 631-640. [CrossRef]

27. Wasdani, K.P.; Prasad, A. The impossibility of social distancing among the urban poor: The case of an Indian slum in the times of COVID-19. Local Environ. 2020, 25, 414-418. [CrossRef]

28. Luo, Y.; Yao, L.; Hu, L.; Zhou, L.; Yuan, F.; Zhong, X. Urban and Rural Disparities of Personal Health Behaviors and the Influencing Factors During the COVID-19 Outbreak in China: Based on an Extended IMB Model. Disaster Med. Public Health Prep. 2020, 2020, 1-5. [CrossRef] [PubMed]

29. Callaghan, T.; Lueck, J.A.; Trujillo, K.L.; Ferdinand, A.O. Rural and Urban Differences in COVID-19 Prevention Behaviors. J. Rural. Health 2021, 37, 287-295. [CrossRef]

30. McFarland, D.; Shen, M.J.; Parker, P.; Meyerson, S.; Holcombe, R.F. Does Hospital Size Affect Patient Satisfaction? Qual. Manag. Health Care 2017, 26, 205-209. [CrossRef] [PubMed]

31. Lubinga, E. 'Uganda Can Protect Chinese Investors but Not Its Own Citizens?' Paradoxical Perspectives in Xenophobic Narratives and Practices Fostering Otherness in Uganda. In Mediating Xenophobia in Africa; Moyo, D., Mpofu, S., Eds.; Palgrave Macmillan: Cham, Switzerland, 2020; pp. 207-227.

32. Roberton, T.; Carter, E.; Chou, V.B.; Stegmuller, A.R.; Jackson, B.D.; Tam, Y.; Sawadogo-Lewis, T.; Walker, N. Early estimates of the indirect effects of the COVID-19 pandemic on maternal and child mortality in low-income and middle-income countries: A modelling study. Lancet Glob. Health 2020, 8, e901-e908. [CrossRef]

33. Dennis, C.-L.; Falah-Hassani, K.; Shiri, R. Prevalence of antenatal and postnatal anxiety: Systematic review and meta-analysis. Br. J. Psychiatry 2017, 210, 315-323. [CrossRef]

34. Ramchandani, P.G.; Richter, L.M.; Norris, S.A.; Stein, A. Maternal Prenatal Stress and Later Child Behavioral Problems in an Urban South African Setting. J. Am. Acad. Child Adolesc. Psychiatry 2010, 49, 239-247. [CrossRef] [PubMed]

35. Biaggi, A.; Conroy, S.; Pawlby, S.; Pariante, C.M. Identifying the women at risk of antenatal anxiety and depression: A systematic review. J. Affect. Disord. 2016, 191, 62-77. [CrossRef] [PubMed]

36. Mappa, I.; Distefano, F.A.; Rizzo, G. Effects of coronavirus 19 pandemic on maternal anxiety during pregnancy: A prospectic observational study. J. Périnat. Med. 2020, 48, 545-550. [CrossRef]

37. Tang, X.; Lu, Z.; Hu, D.; Zhong, X. Influencing factors for prenatal Stress, anxiety and depression in early pregnancy among women in Chongqing, China. J. Affect. Disord. 2019, 253, 292-302. [CrossRef] [PubMed]

38. Manikkam, L.; Burns, J.K. Antenatal depression and its risk factors: An urban prevalence study in KwaZulu-Natal. S. Afr. Med J. 2012, 102, 940-944. [CrossRef]

39. Brittain, K.; Myer, L.; Koen, N.; Koopowitz, S.; Donald, K.A.; Barnett, W.; Zar, H.J.; Stein, D.J. Risk factors for antenatal depression and associations with infant birth outcomes: Results from a south african birth cohort study. Paediatr. Périnat. Epidemiol. 2015, 29, 505-514. [CrossRef]

40. Bilszta, J.L.C.; Tang, M.H.; Meyer, D.; Milgrom, J.; Ericksen, J.; Buist, A.E. Single motherhood versus poor partner relationship: Outcomes for antenatal mental health. Aust. N. Z. J. Psychiatry 2008, 42, 56-65. [CrossRef] 